\title{
Genetic Overlap Among Autism Spectrum Disorders and Other Neuropsychiatric Disorders
}

\author{
Yoshiro Morimoto $^{1,2} \bullet$ Naoki Yamamoto ${ }^{2}$ • Shinji Kanegae ${ }^{2} \bullet$ \\ Ryosuke Matsuzaka² • Hiroki Ozawa1,2 • Akira Imamura ${ }^{1}$ \\ ${ }^{1}$ Child and Adolescent Psychiatry Community Partnership Unit, Nagasaki University \\ Hospital, Nagasaki, Japan; ${ }^{2}$ Department of Neuropsychiatry, Unit of Translational \\ Medicine, Nagasaki University Graduate School of Biomedical Sciences, Nagasaki, Japan
}

Author for correspondence: Akira Imamura, Child and Adolescent Psychiatry Community Partnership Unit, Nagasaki University Hospital, Nagasaki, Japan.

E-mail: aimamura@nagasaki-u.ac.jp

Doi: https://doi.org/10.36255/exonpublications.autismspectrumdisorders.2021. geneticoverlap

\begin{abstract}
Neuropsychiatric disorders such as autism spectrum disorder (ASD), attention-deficit/hyperactivity disorder (ADHD), schizophrenia, bipolar disorder, and major depressive disorder tend to be classified as distinct entities. However, increasing evidence suggests that there are overlaps among these disorders in terms of their genetic risk factors. For example, chromosomal microdeletions and duplications in 16pl1.2 have been reported in individuals with ASD as well as those with schizophrenia and intellectual disability, and common copy number variations have been reported in ASD, schizophrenia, and ADHD. Genome-wide association studies have also revealed common risk variants among ASD, ADHD, bipolar disorder, depression, and schizophrenia. Moreover, next-generation sequencing techniques have revealed overlap in de novo mutations among ASD, schizophrenia, and intellectual disability. Together, these results indicate that
\end{abstract}

In: Autism Spectrum Disorders. Grabrucker AM (Editor). Exon Publications, Brisbane, Australia. ISBN: 978-0-6450017-8-5; Doi: https://doi.org/10.36255/exonpublications. autismspectrumdisorders. 2021

Copyright: The Authors.

License: This open access article is licenced under Creative Commons Attribution-NonCommercial 4.0 International (CC BY-NC 4.0) https://creativecommons.org/licenses/by-nc/4.0/ 
there are shared genetic risks across a range of different disorders. The findings from these studies converge on postsynaptic proteins, such as L-type calcium channels and proteins involved in N-methyl-D-aspartate signaling, and indicate that synaptic mechanisms may underlie many different neuropsychiatric disorders, including ASD. Future studies are likely to reveal further shared mechanisms and contribute to the development of therapies for these disorders.

Keywords: autism spectrum disorder; genetic overlap; genomic copy number variants; genome-wide association studies; next-generation sequencing

\section{INTRODUCTION}

Autism spectrum disorder (ASD) is a neurodevelopmental disorder that is conceptualized as a behavioral syndrome (1). In 1943, Leo Kanner was the first to introduce the term "autism" to define a unique syndrome found in young children in which social and emotional relationships are disrupted (2). Autism is now known as ASD, and is classified as a neurodevelopmental disorder in the Diagnostic and Statistical Manual of Mental Disorders, $5^{\text {th }}$ Edition (DSM-5) by the American Psychiatric Association (3) and in the International Classification of Diseases, $10^{\text {th }}$ Revision by the World Health Organization (4). These classification systems define mental disorders, including ASD, based on the quality and quantity of symptoms. However, the boundaries between each disorder and normality are not always clear. In addition, many symptoms overlap between each disease category, and a single patient may present with features of more than one disorder. In some cases, "comorbidity" is considered to address this overlap of symptoms and disease categories. For example, it is estimated that between 30 and $80 \%$ of children with ASD also have attention-deficit/hyperactivity disorder (ADHD) $(5,6)$.

In recent years, accumulating evidence supports a biological overlap among many psychiatric disorders, which has fueled investigations into the underlying mechanisms of these disorders. In particular, advances in genomic technology and the resulting studies have provided converging evidence to support the hypothesis that genetic risk factors are shared among psychiatric disorders.

\section{RECENT GENETIC INSIGHTS IN ASD}

A systematic review of epidemiological studies of ASD reported a median global prevalence estimate of 62 per 10,000 (7). ASD is a multifactorial disorder and genetic factors appear to be particularly important in the development of ASD. Familial and hereditary studies have reported that if a second child in the family is also diagnosed with ASD, the recurrence rate may be $25-30 \%$ higher compared to sporadic cases of ASD. Furthermore, a high heritability has been reported in ASD; identical twins have a concordance rate of $70-90 \%(8,9)$. It has also been reported that up to $40 \%$ of cases of ASD in children have a genetic cause (e.g., genetic syndromes such as fragile X syndrome, Rett syndrome, tuberous sclerosis, mutations in the phosphatase and tensin homolog (PTEN) 
gene, or structural chromosomal deletions or duplications that can be detected using chromosomal microarrays) $(9,10)$. In addition, metabolic disorders caused by mitochondrial DNA abnormalities are relatively common in individuals with $\operatorname{ASD}(11,12)$.

\section{Chromosomal deletions/duplications and genomic copy number variants $(\mathrm{CNVs})$}

Newer chromosomal single nucleotide polymorphism (SNP) microarrays can identify genetic abnormalities (e.g., microinsertions and microdeletions) that are unable to be identified using high-resolution chromosome methods. Shen et al. (13) performed karyotyping, fragile X DNA testing, and chromosomal microarrays in 933 ASD patients. They identified karyotypic abnormalities in $2.2 \%$ of subjects, fragile X abnormalities in $0.5 \%$ of subjects, and deletions and duplications in $18.2 \%$ of subjects. Deletions or duplications in children with ASD have been reported to involve chromosome regions $1 \mathrm{q} 24.2,2 \mathrm{q} 37.3$, 3p26.2, 4q34.2, 6q24.3, 7q11, 7q35, 13q13.2-q22, 15q1l-q13, 15q22, $16 \mathrm{p} 11.2,17 \mathrm{p} 11.2,22 \mathrm{q} 11.2,22 \mathrm{q} 13$, and Xp22, and additional ASD-associated cytogenetic disorders have also been identified using new ultra-high-resolution microarray technology (e.g., 15q11.2 breakpoint 1-2 [BP1-BP2] deletions) (14-17). Copy number variation or copy number variability is a concept that refers to regions of the genome with variable copy numbers; it includes genomic structural abnormalities such as deletions, duplications, and inversions $(18,19)$. CNVs can be identified by microarrays, and early studies using microarrays reported the presence of CNVs in up to $11 \%$ of ASD patients (20-22). These early studies also reported a high prevalence of de novo CNVs in sporadic ASD cases. These de novo CNVs were considered highly pathogenic because they were not observed in unaffected family members or controls. However, more recent studies of multiplex families have confirmed that some CNVs are present in unaffected relatives of probands, while others are absent in affected relatives, revealing a discrepancy between genotype and phenotype (21, 22). The CNVs that have been reported as associated with ASD include genes that were previously demonstrated to be associated with ASD. Representative ASD-related genes that were identified in these early reports include oxytocin/neurophysin I prepropeptide (OXT), SH3 and multiple ankyrin repeat domains 3 (SHANK3), and neuroligin 4 (NLGN4) (20-23). To date, more than 40 recurrent CNVs have been reported as consistently associated with ASD (24). In addition, some recently identified recurrent CNVs are reportedly associated with characteristic clinical symptoms in addition to $\operatorname{ASD}(25,26)$.

\section{Genome-wide association studies (GWAS)}

GWAS have attracted attention as a method that can identify disease-associated genetic loci, especially for multifactorial diseases. Using GWAS, hundreds of ASD risk loci scattered across all human chromosomes have been identified. In a GWAS of 4,300 children with ASD and 6,500 controls of European descent, six SNPs located on chromosome 5 between the cadherin 10 (CDH10) and cadherin 9 (CDH9) genes, which encode neural cell adhesion molecules, were reported to 
be strongly associated with ASD (27). In recent years, many GWAS of ASD have been conducted, and more than 100 loci have been reported as associated with ASD $(28,29)$. However, the effect sizes of the common ASD-associated variants identified by these GWAS analyses are smaller than expected, and the composition of ASD-associated genes is highly heterogeneous. Currently, no ASDassociated regions have been consistently replicated across multiple GWAS, although there have been several significant genome-wide findings (29). These results suggest that the previously reported GWAS for ASD may be underpowered. The primary cause of underpowered GWAS is a small sample size; thus, larger sample sizes may allow for the discovery of additional ASD candidate loci (30). In addition, several new challenges have been reported to increase the power of GWAS analysis to detect disease-related genes and pathogenic mechanisms. Narita et al. (31) demonstrated that clustering can be used to identify subgroups that are relatively homogeneous in disease etiology. Furthermore, Xie et al. (32) performed an integrated investigation based on Sherlock analysis, spatiotemporal expression patterns, expression analysis, protein-protein interactions, coexpression, and associations with brain structure, and revealed that comprehensive integrated analysis may be an effective way to identify ASD-susceptible variants. Future GWAS analyses using these new methods may lead to the discovery of novel ASD risk genes.

\section{Next-generation sequencing (NGS)}

NGS was put to practical use in the early 2000s and has dramatically increased the speed of genome sequencing. The use of NGS has enabled the performance of whole-genome and whole-exome sequencing, which were not possible using conventional sequencing methods, and has led to the identification of rare genetic variants (variants with minor allele frequencies of less than 1\%) with strong effect sizes. Early NGS analyses of ASD reported a significantly higher proportion of de novo single nucleotide mutations in ASD patients compared with both unaffected sibling control subjects and theoretical expectations (33-36). It has also been reported that, despite the very high heterogeneity of loci at which de novo mutations are identified, a large number of risk genes and regions occur in two major biological areas: synaptic structure and function, and chromatin modification (37-40). In addition, studies with large cohorts have identified new biological regions where risk genes for ASD may functionally intersect or converge. Examples include the relative enrichment genes that are expressed in the fetal brain, transcription factors and RNA-binding proteins, and the targets of fragile X mental retardation protein (FMRP) $(38,39,41,42)$. Recent analyses using NGS have implicated three potential functional pathways to ASD. These include genes and pathways for chromatin remodeling, (e.g., chromodomain helicase DNA binding protein 7 [CHD7], methyl $\mathrm{CpG}$ binding protein 2 [MECP2], DNA [cytosine-5]-methyltransferase 3A [DNMT3A], and PHD finger protein 2 [PHF2]), Wnt (e.g., CHD8, paired box protein Pax-5 [PAX5], and transcriptional regulator ATRX [ATRX]), other signaling super-pathways (e.g., G protein-coupled receptors [GPCRs], extracellular signal-regulated kinases [ERKs], RET proto-oncogene $[R E T]$, and protein kinase B [AKT] pathways) (43), and mitochondrial dysfunction in ASD (44). 


\section{GENETIC OVERLAP AMONG ASD AND OTHER NEUROPSYCHIATRIC DISORDERS}

In recent years, the relationship and overlap between functional psychiatric disorders (e.g., schizophrenia and bipolar disorder) and neurodevelopmental disorders has been discussed. These disorders are considered to be a continuum of neurodevelopmental disturbances that are induced by genetic and environmental factors $(45,46)$. This model suggests that multiple psychiatric disorders, including ASD, may form a spectrum with a common biological basis and differing grades of severity. Recent genomic analyses have supported such a model, and have led to the identification of common genetic variants and biological factors across a range of neurodevelopmental disorders.

\section{CNV studies}

As noted previously in this chapter, early CNV studies reported striking results regarding the relationship between genotype and phenotype. As the size of analyzed cohorts has increased, duplications and deletions of ASD-related regions have been demonstrated to be independently associated with ASD risk $(47,48)$. As de novo CNV studies have extended across psychiatric research populations, it has become increasingly difficult to identify ASD-associated CNVs that do not also confer some risk for another psychiatric disorder or phenotype, including schizophrenia, bipolar disorder, ADHD, specific language impairment, and a leftward shift in intelligence quotient among carriers. Sanders et al. (48) screened 69 loci in 1,105 children with unexplained intellectual disability (ID) and identified seven children (0.7\%) with 16p11.2 deletion, which has been linked to ASD. In addition, McCarthy et al. (49) reported an association between 16p11.2 microduplication and schizophrenia in two large cohorts. Furthermore, a meta-analysis of multiple psychiatric datasets revealed significant associations between 16 p11.2 microduplication and schizophrenia $\left(p=4.8 \times 10^{-7}\right)$, bipolar disorder $(p=0.017)$, and ASD $\left(p=1.9 \times 10^{-7}\right)$. In a study of individuals from Iceland and Norway, Gudmundsson et al. (50) reported that eight CNVs that had previously been linked to schizophrenia and ASD were also associated with ADHD (deletions in 2p16.3 [neurexin 1; NRXN1], 15q11.2, 15q13.3 [BP4 and BP4.5-BP5], and $22 \mathrm{q} 11.21$, and duplications at $1 \mathrm{q} 21.1$ distal, $16 \mathrm{p} 11.2$ proximal, 16p13.11, and 22q11.21). This result highlights the pleiotropic effects of neuropsychiatric CNVs and provides evidence to support the concept that ADHD, ASD, and schizophrenia may be related neurodevelopmental disorders rather than distinct entities (50).

Zarrei et al. (51) used microarrays to genotype 2,691 subjects with diagnosed neurodevelopmental disorders (204 with schizophrenia, 1,838 with ASD, 427 with ADHD, and 222 with obsessive-compulsive disorder) and 1,769 family members (mostly parents). Clinically significant CNVs (CNVs in the broad sense) were identified in 284 (10.5\%) subjects, including 22 (10.8\%) with schizophrenia, 209 (11.4\%) with ASD, 40 (9.4\%) with ADHD, and 13 (5.6\%) with obsessive-compulsive disorder. In addition, these authors searched for genes affected by different CNVs in multiple disorders. Examples of 
neurodevelopmental disorder-related genes linked across multiple disorders include NRXN1, SEH1 like nucleoporin (SEH1L), low density lipoprotein receptor class A domain containing 4 (LDLRAD4), G protein subunit alpha L (GNAL), G protein subunit gamma 13 (GNG13), makorin ring finger protein 1 (MKRN1), dynactin subunit 2 (DCTN2), kinase non-catalytic C-lobe domain containing 1 (KNDC1), protein-L-isoaspartate O-methyltransferase domain-containing protein 2 (PCMTD2), kinesin family member 5A (KIF5A), synemin (SYNM), and the long non-coding RNAs AK127244 and PTCHD1-AS. These findings indicate that CNVs impacting the same genes may potentially contribute to the etiology of multiple neurodevelopmental disorders (51).

\section{GWAS studies}

The Cross-Disorder Group of the Psychiatric Genomics Consortium has attempted to identify the specific variants that underlie the genetic effects common to five psychiatric disorders: ASD, ADHD, bipolar disorder, major depression, and schizophrenia. They analyzed SNP data from 33,332 cases and 27,888 controls of European ancestry. Four SNPs exceeded the cutoff value $\left(p<5 \times 10^{-8}\right)$ for genome-wide significance: regions on chromosomes $3 \mathrm{p} 21$ and 10q24, and SNPs within two L-type calcium voltage-gated channel subunits, alpha 1 C (CACNA1C) and beta 2 (CACNB2) (52). In addition, Grove et al. (53) conducted a genome-wide association meta-analysis of 18,381 ASD cases and 27,969 controls, using a unique Danish population resource to substantially increase the sample size. They leveraged the results of GWAS for three phenotypes (schizophrenia, major depression, and education level) with significant overlap in genetic architecture to identify seven loci that were shared with other traits using a strict significance level (53). Furthermore, Wu et al. (54) conducted a meta-analysis of GWAS for schizophrenia $(n=65,967)$, bipolar disorder $(n=41,653), \operatorname{ASD}(n=46,350), \operatorname{ADHD}(n=55,374)$, and depression $(n=688,809)$. This meta-analysis identified significant enrichment of overlapping genes among different disorders and identified a group of cross-disease genes. Seven genesgamma-aminobutyric acid type B receptor subunit 1 (GABBR1), glycosyltransferase 8 domain containing 1 (GLT8D1); histones H1.5 (HIST1H1B), H2B type 1-N (HIST1H2BN), and H4 (HIST1H4L); potassium voltage-gated channel subfamily B member 1 (KCNB1); and DCC netrin 1 receptor (DCC) - were commonly associated with four of the five psychiatric disorders. The sortilin related VPS10 domain containing receptor 3 (SORCS3) gene was also highlighted because it was involved in all five conditions in the study (54).

A polygenic risk score for common variants allows us to verify that genetic risk is shared among different disorders. Using polygenic risk scores, it has been reported that alleles overexpressed in patients with schizophrenia are also overexpressed in patients with bipolar disorder and ADHD, but not ASD (55-57). Moreover, González-Peñas et al. (58) reported genetic overlap among five disorders (schizophrenia, major depressive disorder, ADHD, obsessivecompulsive disorder, and anxiety disorders) and Asperger syndrome or other ASD subtypes using polygenic risk scores. They reported that the risk of schizophrenia, ADHD, and major depressive disorder is transmitted from parents to children with Asperger syndrome, but that this does not occur in the other ASD subtypes. Their results support the idea that Asperger syndrome is qualitatively 
different from the rest of the ASD subtypes, and indicates a genetic overlap between Asperger syndrome and ADHD, major depressive disorder, and schizophrenia (58). Furthermore, polygenic risk scores in a recent GWAS of multiple psychiatric disorders revealed a high correlation between schizophrenia and bipolar disorder, a moderate correlation between major depressive disorder and schizophrenia, major depressive disorder and bipolar disorder, major depressive disorder and ADHD, and a small but significant correlation between schizophrenia and ASD. However, other reports have identified no correlations between other pairs of disorders, such as ASD and ADHD, bipolar disorder and ADHD, and schizophrenia and ADHD. These results are unexpected given that there is considerable phenotypic overlap between these disease pairs, and that previous family, twin, and linkage studies have suggested the presence of common genetic risk factors (59-64).

\section{NGS studies}

Fromer et al. (65) reported that de novo mutations in genes encoding proteins with specific functions are prevalent in schizophrenic patients (e.g., glutamatergic postsynaptic proteins comprising activity-regulated cytoskeleton-associated protein [ARC] and N-methyl-D-aspartate receptor [NMDAR] complexes). Moreover, genes with de novo mutations in schizophrenia overlap with those affected by de novo mutations in ASD and ID, but not in controls (65). The most extensive exome sequencing study to date ( $n=35,584$ total samples, 11,986 with ASD), conducted by Satterstrom et al. (66), reported an overlap of genes affected by de novo mutations in ASD and ID, but not in controls. Furthermore, loss-of-function mutations in schizophrenia were also enriched in a small group of genes $(n=7)$ with recurrent loss-of-function de novo mutations in ASD $(p=0.0018)$ and ID $(p=0.019)$. These mutations clustered in sodium voltage-gated channel alpha subunit 2 (SCN2A) and pogo transposable element derived with ZNF domain (POGZ). These genes have been established as ASD-associated genes. Other genes, such as discs large MAGUK scaffold protein 2 (DLG2) and SHANK1, which have been implicated in loss-of-function gene mutations in other neurodevelopmental disorders, were also identified. Thus, there is a clear overlap among schizophrenia, ASD, and ID (66). The list of rare risk alleles for ASD and other psychiatric disorders remains relatively small; as more rare risk alleles are discovered in each diagnostic category, more overlapping genes may be identified.

\section{POTENTIAL BIOLOGICAL MECHANISMS FOR SHARED GENETIC RISK}

Recently, GWAS, CNV, and NGS studies have suggested the existence of a set of biological processes that are common to multiple psychiatric disorders. These include L-type calcium channels, postsynaptic scaffolding proteins involved in $\mathrm{N}$-methyl-D-aspartate (NMDA) signal transduction, proteins that interact with ARC (referred to as the ARC complex) (67), brain-expressed genes that are repressed by FMRP $(65,68)$, and NRXN1 (an associated CNV locus) (69). 
However, it is not yet fully understood how the biological pathways that are commonly associated with these multiple psychiatric disorders can cause effects across current diagnostic boundaries. Elucidating the biological processes commonly involved in the risk of ASD and related disorders will allow for a more detailed understanding of the pathomechanisms of each disease, and may lead to the development of novel treatments and biomarkers.

\section{CONCLUSION}

In this chapter, we reviewed recent ASD genetic studies and presented evidence of common genetic factors in multiple psychiatric disorders, including ASD, that spread beyond the diagnostic categories of conventional psychiatry. These findings suggest that some etiological mechanisms that are present in the current diagnostic categories may not be specific to each disorder. Future studies are likely to reveal robust risk alleles and mechanisms that are associated with higher disease risks. However, strict regulations on genetic counseling, confidentiality, and data protection need to be applied to the handling of genetic information of individuals with such high disease risk (70). Further genetic research is expected to reveal new genetic risk factors and etiologies common to multiple psychiatric disorders, and to contribute to the discovery of new therapeutic targets.

Acknowledgment: We thank Bronwen Gardner, PhD, from Edanz Group (https:// jp.edanz.com/ac) for editing a draft of this manuscript. This work was supported by JSPS KAKENHI (grant number 20K16650) as well as by the Takeda Science Foundation (to YM).

Conflict of interest: The authors declare no potential conflicts of interest with respect to research, authorship and/or publication of this manuscript.

Copyright and permission statement: The authors confirm that the materials included in this chapter do not violate copyright laws. Where relevant, appropriate permissions have been obtained from the original copyright holder(s), and all original sources have been appropriately acknowledged or referenced.

\section{REFERENCES}

1. Tordjman S, Cohen D, Anderson GM, Botbol M, Canitano R, Coulon N, et al. Reprint of "Reframing autism as a behavioral syndrome and not a specific mental disorder: Implications of genetic and phenotypic heterogeneity". Neurosci Biobehav Rev. 2018;89:132-50. https://doi.org/10.1016/j. neubiorev.2018.01.014

2. Kanner L. Autistic disturbances of affective contact. Nervous Child. 1943;32:217-53.

3. American Psychiatric Association. Diagnostic and statistical manual of mental disorders. 5th ed. Washington DC, USA: American Psychiatric Association; 2013. 947 p. https://doi.org/10.1176/appi. books. 9780890425596

4. World Health Organization. ICD-10: International statistical classification of diseases and related health problems: 10th revision. 2nd ed. Geneva, Switzerland: World Health Organization; 2004. 125 p. 
5. Simonoff E, Pickles A, Charman T, Chandler S, Loucas T, Baird G. Psychiatric disorders in children with autism spectrum disorders: Prevalence, comorbidity, and associated factors in a populationderived sample. J Am Acad Child Adolesc Psychiatry. 2008;47(8):921-9. https://doi.org/10.1097/ CHI.0b013e318179964f

6. Lee DO, Ousley OY. Attention-deficit hyperactivity disorder symptoms in a clinic sample of children and adolescents with pervasive developmental disorders. J Child Adolesc Psychopharmacol. 2006;16(6):737-46. https://doi.org/10.1089/cap.2006.16.737

7. Elsabbagh M, Divan G, Koh Y-J, Kim YS, Kauchali S, Marcín C, et al. Global prevalence of autism and other pervasive developmental disorders. Autism Res. 2012;5:160-79. https://doi.org/10.1002/ aur. 239

8. Abrahams BS, Geschwind DH. Advances in autism genetics: On the threshold of a new neurobiology. Nat Rev Genet. 2008;9(5):341-55. https://doi.org/10.1038/nrg2346

9. Schaefer GB, Mendelsohn NJ, Professional Practice and Guidelines Committee. Clinical genetics evaluation in identifying the etiology of autism spectrum disorders: 2013 guideline revisions. Genet Med. 2013;15(5):399-407. https://doi.org/10.1038/gim.2013.32

10. Schaefer GB, Mendelsohn NJ, Professional Practice Guidelines Committee. Clinical genetics evaluation in identifying the etiology of autism spectrum disorders. Genet Med. 2008;10(4):301-5. https:// doi.org/10.1097/GIM.0b013e31816b5cc9

11. Rose S, Niyazov DM, Rossignol DA, Golenthal M., Kahler SG, Frye RE. Clinical and molecular characteristics of mitochondrial dysfunction in autism spectrum disorder. Mol Diagn Ther. 2018;22(5):571-93. https://doi.org/10.1007/s40291-018-0352-x

12. Dhillon S, Hellings JA, Butler MG. Genetics and mitochondrial abnormalities in autism spectrum disorders: A review. Curr Genom. 2011;12(5):322-32. https://doi. org/10.2174/138920211796429745

13. Shen Y, Dies KA, Holm IA, Bridgemohan C, Sobeih MM, Caronna EB, et al. Clinical genetic testing for patients with autism spectrum disorders. Pediatrics. 2010;125(4):727-35. https://doi.org/10.1542/ peds.2009-1684

14. Miles JH. Autism spectrum disorders-A genetics review. Genet Med. 2011;13(4):278-94. https://doi. org/10.1097/GIM.0b013e3181ff67ba

15. Ho KS, Wassman ER, Baxter AL, Hensel CH, Martin MM, Prasad A, et al. Chromosomal microarray analysis of consecutive individuals with autism spectrum disorders using an ultra-high resolution chromosomal microarray optimized for neurodevelopmental disorders. Int J Mol Sci. 2016;17(12):2070. https://doi.org/10.3390/ijms17122070

16. Fernandez BA, Roberts W, Chung B, Weksberg R, Meyn S, Szatmari P, et al. Phenotypic spectrum associated with de novo and inherited deletions and duplications at 16p11.2 in individuals ascertained for diagnosis of autism spectrum disorder. J Med Genet. 2010;47(3):195-203. https://doi.org/10.1136/ jmg.2009.069369

17. Miller DT, Shen Y, Weiss LA, Korn J, Anselm I, Bridgemohan C, et al. Microdeletion/duplication at $15 q 13.2 q 13.3$ among individuals with features of autism and other neuropsychiatric disorders. J Med Genet. 2009;46(4):242-8. https://doi.org/10.1136/jmg.2008.059907

18. Malhotra D, Sebat J. CNVs: harbingers of a rare variant revolution in psychiatric genetics. Cell. 2012 Mar 16;148(6):1223-41. https://doi.org/10.1016/j.cell.2012.02.039

19. Zarrei M, MacDonald JR, Merico D, Scherer SW. A copy number variation map of the human genome. Nat Rev Genet. 2015 Mar;16(3):172-83. https://doi.org/10.1038/nrg3871

20. Sebat J, Lakshmi B, Malhotra D, Troge J, Lese-Martin C, Walsh T, et al. Strong association of de novo copy number mutations with autism. Science. 2007;316(5823):445-9. https://doi.org/10.1126/ science. 1138659

21. Christian SL, Brune CW, Sudi J, Kumar RA, Liu S, Karamohamed S, et al. Novel submicroscopic chromosomal abnormalities detected in autism spectrum disorder. Biol Psychiatry. 2008;63(12):1111-7. https://doi.org/10.1016/j.biopsych.2008.01.009

22. Marshall CR, Noor A, Vincent JB, Lionel AC, Feuk L, Skaug J., et al. Structural variation of chromosomes in autism spectrum disorder. Am J Hum Genet. 2008;82(2):477-88. https://doi.org/10.1016/j. ajhg.2007.12.009 
23. Velinov M. Genomic Copy Number Variations in the Autism Clinic-Work in Progress. Front Cell Neurosci. 2019 Feb 19;13:57. https://doi.org/10.3389/fncel.2019.00057

24. Takumi T, Tamada K. CNV biology in neurodevelopmental disorders. Curr Opin Neurobiol 2018;48:183-92. https://doi.org/10.1016/j.conb.2017.12.004

25. Bernier R, Steinman KJ, Reilly B, Wallace AS, Sherr EH, Pojman N, et al. Clinical phenotype of the recurrent 1q21.1 copy-number variant. Genet Med. 2016;18(4):341-9. https://doi.org/10.1038/ gim.2015.78

26. D'Angelo D, Lebon S, Chen Q, Martin-Brevet S, Snyder LG, Hippolyte L, et al. Defining the effect of the 16pl1.2 duplication on cognition, behavior, and medical comorbidities. JAMA Psychiatry. 2016;73(1):20-30. https://doi.org/10.1001/jamapsychiatry.2015.2123

27. Wang K, Zhang H, Ma D, Bucan M, Glessner JT, Abrahams BS, et al. Common genetic variants on 5p14.1 associate with autism spectrum disorders. Nature. 2009;459(7246):528-33. https://doi. org/10.1038/nature07999

28. Delvin B, Scherer SW. Genetic architecture in autism spectrum disorder. Curr Opin Genet Dev. 2012;22(3):229-37. https://doi.org/10.1016/j.gde.2012.03.002

29. Geschwind DH, State MW. Gene hunting in autism spectrum disorder: On the path to precision medicine. Lancet Neurol. 2015;14(11):1109-20. https://doi.org/10.1016/S1474-4422(15)00044-7

30. Visscher PM, Wray NR, Zhang Q, Sklar P, McCarthy MI, Brown MA, et al. 10 Years of GWAS discovery: biology, function, and translation. Am J Hum Genet. 2017;101(1):5-22. https://doi.org/10.1016/j. ajhg.2017.06.005

31. Sanders SJ, Murtha MT, Gupta AR, Murdoch JD, Raubeson MJ, Willsey AJ, et al. De novo mutations revealed by whole-exome sequencing are strongly associated with autism. Nature. 2012;485(7397):237-41. https://doi.org/10.1038/nature10945

32. Narita A, Nagai M, Mizuno S, Ogishima S, Tamiya G, Ueki M, et al. Clustering by phenotype and genome-wide association study in autism. Transl Psychiatry. 2020 Aug 17;10(1):290. https://doi. org/10.1038/s41398-020-00951-x

33. Xie X, Li L, Wu H, Hou F, Chen Y, Xue Q, et al. Comprehensive Integrative Analyses Identify TIGD5 rs75547282 as a Risk Variant for Autism Spectrum Disorder. Autism Res. 2021 Apr;14(4):631-644. https://doi.org/10.1002/aur.2466

34. Neale BM, Kou Y, Liu L, Ma'ayan A, Samocha KE, Sabo A, et al. Patterns and rates of exonic de novo mutations in autism spectrum disorders. Nature. 2012;485(7397):242-5. https://doi.org/10.1038/ naturel1011

35. O'Roak BJ, Vives L, Girirajan S, Karakoc E, Krumm N, Coe BP, et al. Sporadic autism exomes reveal a highly interconnected protein network of de novo mutations. Nature. 2012;485(7397):246-50. https://doi.org/10.1038/nature10989

36. Iossifov I, Ronemus M, Levy D, Wang Z, Hakker I, Rosenbaum J, et al. De novo gene disruptions in children on the autistic spectrum. Neuron. 2012;74(2):285-99. https://doi.org/10.1016/j. neuron.2012.04.009

37. O'Roak BJ, Deriziotis P, Lee C, Vives L, Schwartz JJ, Girirajan S, et al. Exome sequencing in sporadic autism spectrum disorders identifies severe de novo mutations. Nat Genet. 2011;43(6):585-9. https://doi.org/10.1038/ng.835

38. Iossifov I, O'Roak BJ, Sanders SJ, Ronemus M, Krumm N, Levy D, et al. The contribution of de novo coding mutations to autism spectrum disorder. Nature. 2014;515(7526):216-21. https://doi. org/10.1038/nature13908

39. De Rubeis S, He X, Goldberg AP, Poultney CS, Samocha K, Cicek AE, et al. Synaptic, transcriptional, and chromatin genes disrupted in autism. Nature. 2014;515(7526):209-15. https://doi.org/10.1038/ nature 13772

40. Gilman SR, Iossifov I, Levy D, Ronemus M, Wigler M, Vitkup D. Rare de novo variants associated with autism implicate a large functional network of genes involved in formation and function of synapses. Neuron. 2011;70(5):898-907. https://doi.org/10.1016/j.neuron.2011.05.021

41. Sestan N, State MW. Lost in translation: Traversing the complex path from genomics to therapeutics in autism spectrum disorder. Neuron. 2018;100(2):406-23. https://doi.org/10.1016/j. neuron.2018.10.015 
42. Willsey AJ, Morris MT, Wang S, Willsey HR, Sun N, Teerikorpi N, et al. The Psychiatric Cell Map Initiative: A convergent systems biological approach to illuminating key molecular pathways in neuropsychiatric disorders. Cell. 2018;174(3):505-20. https://doi.org/10.1016/j.cell.2018.06.016

43. Genovese A, Butler MG. Clinical assessment, genetics, and treatment approaches in autism spectrum disorder (ASD). Int J Mol Sci. 2020;21(13):4726. https://doi.org/10.3390/ijms21134726

44. Varga NA, Pentelenyi K, Balicza P, Gezsi A, Remenyi V, Harsfalvi V, et al. Mitochondrial dysfunction and autism: Comprehensive genetic analyses of children with autism and mtDNA deletion. Behav Brain Funct. 2018;14(1):4. https://doi.org/10.1186/s12993-018-0135-x

45. Craddock N, Owen MJ. The Kraepelinian dichotomy - going, going... but still not gone. Br J Psychiatry. 2010;196(2):92-5. https://doi.org/10.1192/bjp.bp.109.073429

46. Owen MJ. Intellectual disability and major psychiatric disorders: A continuum of neurodevelopmental causality. Br J Psychiatry. 2012;200(4):268-9. https://doi.org/10.1192/bjp.bp.111.105551

47. Levy D, Ronemus M, Yamrom B, Lee YH, Leotta A, Kendall J, et al. Rare de novo and transmitted copy-number variation in autistic spectrum disorders. Neuron. 2011;70(5):886-97. https://doi. org/10.1016/j.neuron.2011.05.015

48. Sanders SJ, Ercan-Sencicek AG, Hus V, Luo R, Murtha MT, Moreno-De-Luca D, et al. Multiple recurrent de novo CNVs, including duplications of the $7 q 11.23$ Williams syndrome region, are strongly associated with autism. Neuron. 2011;70(5):863-85. https://doi.org/10.1016/j. neuron.2011.05.002

49. McCarthy SE, Makarov V, Kirov G, Addington AM, McClellan J, Yoon S, et al. Microduplications of 16pl1.2 are associated with schizophrenia. Nat Genet. 2009;41(11):1223-7. https://doi.org/10.1038/ ng. 474

50. Gudmundsson OO, Walters GB, Ingason A, Johansson S, Zayats T, Athanasiu L, et al. Attention-deficit hyperactivity disorder shares copy number variant risk with schizophrenia and autism spectrum disorder. Transl Psychiatry. 2019;9(1):258. https://doi.org/10.1038/s41398-019-0599-y

51. Zarrei M, Burton CL, Engchuan W, Young EJ, Higginbotham EJ, MacDonald JR, et al. A large data resource of genomic copy number variation across neurodevelopmental disorders. NPJ Genom Med. 2019;4:26. https://doi.org/10.1038/s41525-019-0098-3

52. Cross-Disorder Group of the Psychiatric Genomics Consortium. Identification of risk loci with shared effects on five major psychiatric disorders: a genome-wide analysis. Lancet. 2013;381(9875):1371-9. https://doi.org/10.1016/S0140-6736(12)62129-1

53. Grove J, Ripke S, Als TD, Mattheisen M, Walters RK, Won H, et al. Identification of common genetic risk variants for autism spectrum disorder. Nat Genet. 2019;51(3):431-44. https://doi.org/10.1038/ s41588-019-0344-8

54. Wu Y, Cao H, Baranova A, Huang H, Li S, Cai L, et al. Multi-trait analysis for genome-wide association study of five psychiatric disorders. Transl Psychiatry. 2020;10(1):209. Erratum in: Transl Psychiatry. 2020;10(1):234. https://doi.org/10.1038/s41398-020-00924-0

55. Purcell SM, Wray NR, Stone JL, Visscher PM, O'Donovan MC, Sullivan PF, et al. Common polygenic variation contributes to risk of schizophrenia and bipolar disorder. Nature. 2009;460(7256):748-52. https://doi.org/10.1038/nature08185

56. Hamshere ML, Stergiakouli E, Langley K, Martin J, Holmans P, Kent L, et al. Shared polygenic contribution between childhood attention-deficit hyperactivity disorder and adult schizophrenia. $\mathrm{Br} \mathrm{J}$ Psychiatry. 2013;203(2):107-11. https://doi.org/10.1192/bjp.bp.112.117432

57. Vorstman JA, Anney RJ, Derks EM, Gallagher L, Gill M, de Jonge MV, et al. No evidence that common genetic risk variation is shared between schizophrenia and autism. Am J Med Genet B Neuropsychiatr Genet. 2013;162B(1):55-60. https://doi.org/10.1002/ajmg.b.32121

58. González-Peñas J, Costas JC, García-Alcón A, Penzol MJ, Rodríguez J, Rodríguez-Fontenla C, et al. Psychiatric comorbidities in Asperger syndrome are related with polygenic overlap and differ from other Autism subtypes. Transl Psychiatry. 2020 Jul 30;10(1):258. https://doi.org/10.1038/ s41398-020-00939-7

59. Lee SH, Ripke S, Neale BM, Faraone SV, Purcell SM, Perlis RH, et al. Genetic relationship between five psychiatric disorders estimated from genome-wide SNPs. Nat Genet. 2013;45(9):984-94. https://doi. org/10.1038/ng.2711 
60. Larsson H, Rydén E, Boman M, Långström N, Lichtenstein P, Landén M. Risk of bipolar disorder and schizophrenia in relatives of people with attention-deficit hyperactivity disorder. Br J Psychiatry. 2013;203(2):103-6. https://doi.org/10.1192/bjp.bp.112.120808

61. Rommelse NN, Franke B, Geurts HM, Hartman CA, Buitelaar JK. Shared heritability of attention-deficit/hyperactivity disorder and autism spectrum disorder. Eur Child Adolesc Psychiatry. 2010;19(3):281-95. https://doi.org/10.1007/s00787-010-0092-x

62. Nijmeijer JS, Arias-Vásquez A, Rommelse NN, Altink ME, Anney RJ, Asherson P, et al. Identifying loci for the overlap between attention-deficit/hyperactivity disorder and autism spectrum disorder using a genome-wide QTL linkage approach. J Am Acad Child Adolesc Psychiatry. 2010;49(7):675-85. https://doi.org/10.1016/j.jaac.2010.03.015

63. Mulligan A, Anney RJ, O'Regan M, Chen W, Butler L, Fitzgerald M, et al. Autism symptoms in attention-deficit/hyperactivity disorder: A familial trait which correlates with conduct, oppositional defiant, language and motor disorders. J Autism Dev Disord. 2009;39(2):197-209. https://doi.org/10.1007/ sl0803-008-0621-3

64. Faraone SV, Biederman J, Wozniak J. Examining the comorbidity between attention deficit hyperactivity disorder and bipolar I disorder: A meta-analysis of family genetic studies. Am J Psychiatry. 2012;169(12):1256-66. https://doi.org/10.1176/appi.ajp.2012.12010087

65. Fromer M, Pocklington AJ, Kavanagh DH, Williams HJ, Dwyer S, Gormley P, et al. De novo mutations in schizophrenia implicate synaptic networks. Nature. 2014;506(7487):179-84. https://doi. org/10.1038/nature12929

66. Satterstrom FK, Kosmicki JA, Wang J, Breen MS, De Rubeis S, An JY, et al. Large-scale exome sequencing study implicates both developmental and functional changes in the neurobiology of autism. Cell. 2020;180(3):568-584.e23.

67. Kirov G, Pocklington AJ, Holmans P, Ivanov D, Ikeda M, Ruderfer D, et al. De novo CNV analysis implicates specific abnormalities of postsynaptic signalling complexes in the pathogenesis of schizophrenia. Mol Psychiatry. 2012;17(2):142-53. https://doi.org/10.1038/mp.2011.154

68. Niere F, Wilkerson JR, Huber KM. Evidence for a fragile X mental retardation protein-mediated translational switch in metabotropic glutamate receptor-triggered Arc translation and long-term depression. J Neurosci. 2012;32(17):5924-36. https://doi.org/10.1523/JNEUROSCI.4650-11.2012

69. Kirov G, Rujescu D, Ingason A, Collier DA, O'Donovan MC, Owen MJ. Neurexin I (NRXN1) deletions in schizophrenia. Schizophr Bull. 2009;35(5):851-4. https://doi.org/10.1093/schbul/sbp079

70. Gershon ES, Alliey-Rodriguez N. New ethical issues for genetic counseling in common mental disorders. Am J Psychiatry. 2013;170(9):968-76. https://doi.org/10.1176/appi.ajp.2013.12121558 